\title{
The Reactivities In Different HgCl Substitution Sites Of PCDDs/PCDFs
}

$$
\text { Zhengyang Gao }{ }^{1, a} \text {, Peng Ji }{ }^{1, b}
$$

1School of Energy and power Engineering, North China Electric power University, Baoding 071003, China

\author{
agaozhyang@163.com, ${ }^{b} 1136139858 @ q q . c o m$
}

Keywords: PCDD/Fs; HgCl group; HOMO/LUMO; electrostatic potential energy extreme points.

\begin{abstract}
PCDD/Fs and mercury are contaminants with high toxicity and heavy harm in power plants especially in waste incineration plants, and they could produce polychlorinated and mercury chloride based Dioxins under the environment of high temperature and high pressure. PeCDD, which replaces the positions of $1,2,3,6,7$ sites on PCDDs, has widely sources and high toxicity. Polychlorinated and mercury chloride based Dioxins are dioxin-like substances. DFT (Density Functional Theory) is used to optimize the structures and then calculate HOMO/LUMO and the electrostatic potential energy extreme value is calculated in Multiwfn. By analyzing the bond length and bond angle, HOMO/LUMO and electrostatic potential energy extreme points, it is known that the $\mathrm{Cl}$ on $\mathrm{HgCl}$ groups is easy to lose electron, known as nucleophilic reaction. All the atoms but the $\mathrm{HgCl}$ group and the $\mathrm{H}$ atoms are able to adsorb electron, and the $\mathrm{Cl}$ atom on $\mathrm{C}-\mathrm{Cl}$ bond is most likely to react electrophilically.
\end{abstract}

\section{Introduction}

Dioxins are recognized as the Persistent Organic Pollutant (POPs). The dioxins, in the atmospheric environment, have complex origins, such as the coal-fired power plants and waste incineration plants which are so close to our daily life [1]. At the same time, there are many Dioxin-like substances in the air except the typical PCDD/Fs, such as the polychlorinated and mercury chloride based dioxins. Their structures and properties are closed to the PCDD/Fs, and more and more researches show that the Dioxin-like substances have a great influence on the environment and especially on human, which is beyond our imagination [2-5].

Dr. Zhang, Gang et al [6] have researched that the contents of $\mathrm{Hg}$ and PCDD/Fs in the contaminants from the waste incineration plants occupy a large proportion. The emission range of Dioxins in the typical waste incineration power plants in china is $0.0042 \sim 7.90 \mathrm{ng} \mathrm{I}-\mathrm{TEQ} / \mathrm{nm}^{3}$, and the average value is $0.561 \mathrm{ng} \mathrm{I}-\mathrm{TEQ} / \mathrm{nm}^{3}$, and there is about $85 \%$ of the emissions in the waste incineration power plants conform to the limiting value 1 . 0ng I-TEQ $/ \mathrm{nm}^{3}$ which is decided by Living Garbage Burning Pollution Control Standards (GB18485-2014). It can be inferred that there has some reactions between $\mathrm{Hg}$ and $\mathrm{PCDD} / \mathrm{Fs}$. $\mathrm{Hu}[7]$ et al have assessed the emission factor of atmospheric mercury is $(126.7 \pm 109.0) \mu \mathrm{g} \cdot \mathrm{kg}^{-1}$ in the waste incineration plants of many different cities in china, which is calculated by the mercury removal efficiency and the level of Hg in Flue gas mercury facilities . Emissions atmospheric mercury can be extrapolated in the waste incineration plants in 2010, which is 6.1t, and the emission of organic mercury is about $0.19 t$. Many researches are revealed that the emissions of $\mathrm{Hg}$ in the waste incineration plants increases by years. The limit of the $\mathrm{Hg}$ emissions from waste incineration power plants is decided by the Living Garbage Burning Pollution Control Standards (GB18485-2014), which is $1.0 \mathrm{mg} / \mathrm{m}^{3}$. So the problem of $\mathrm{Hg}$ emissions in the plants is really serious [8].

Chen, Tong et al [9] have studied that PCDDs have a negative correlation with the heavy metal elements and $\mathrm{PH}$, which means that they may have a good correlation, so that they can produce the polychlorinated and mercury chloride based dioxins in a series of reactions. Jensen [10] from Sweden have proved that the $\mathrm{Hg}^{2+}$ from the power plants can change into methyl mercury after a series of reactions, and the methyl mercury may change into 2-(Chloromercurio) phenol. In the formation 
mechanism of PCDDs, Gao Rui et al. have researched that halogenated phenol can be the precursor of PCDDs, and these precursors play a very important role in producing PCDDs, and almost all of the PCDDs are produced by this way. Polychlorinated and mercury chloride based dioxins are a kind of dioxin-like substances, they have the same characters. So 2-(Chloromercurio) phenol may be one of the precursors of the polychlorinated and mercury chloride based dioxins. By the same time, 2-(Chloromercurio) phenol is also a kind of highly toxic pesticides, so there may produce the polychlorinated and mercury chloride based dioxins in the soil. By this way, polychlorinated and mercury chloride based dioxins are very likely to accumulate in human's bodies. Once they can be produced in soils, the society will face a huge crisis. So studying the character of them becomes very important.

\section{Computing Method}

\subsection{Theoretical Method.}

As there are few researches on polychlorinated and mercury chloride based dioxins, there is a little knowledge on the structure, stability and the active sites of this substance. According to Zhao Jian-Ying's research[12], structures are calculated by using B3LYP/6-31+G(d, p) for the C, H, O, CL and SDD for the Hg in Gaussian 09, which is precise and rapid. Then the HOMO/LUMO comes out. By the same time, the electrostatic potential energy extreme values and their positions are calculated by multiwfn. The structural characteristics and reactivity points of polychlorinated and mercury chloride based dioxins can be inferred.

\subsection{Theoretical Method.}

Polychlorinated and mercury chloride based dioxins have a lot of homogeneous forms like PCDDs, which are changed with the attached positions and the number of $\mathrm{HgCl}$ groups and chorine groups. Among the 210 kinds of different structures in PCDDs, PeCDD has the characters of high toxicity, widely distribution. So 1, 2, 3, 6, 7-PCDDs have a good representative and universality. The homogeneous forms which take the place of these four positions can be regard as the typical structure of polychlorinated and mercury chloride based dioxins, the characters can be inferred from polychlorinated and mercury chloride based dioxins from this kind of structure.

The electrons orbits and the electrostatic energy points are studied for two $\mathrm{HgCl}$ groups. There are 10 situations when there are two $\mathrm{HgCl}$ groups, shown in picture 1

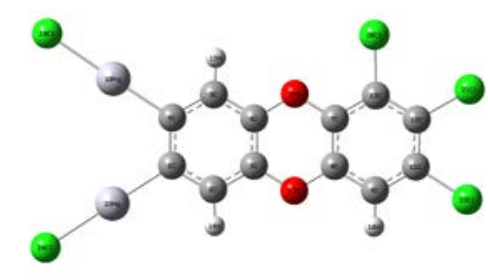

D1: 1, 2, 3-Cl 6, 7-HgCl PCDD

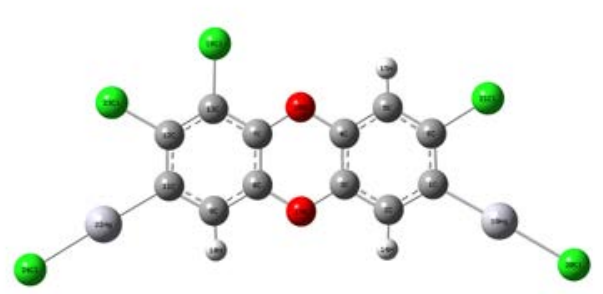

D3: 1, 2, 7-Cl 3, 6-HgCl PCDD

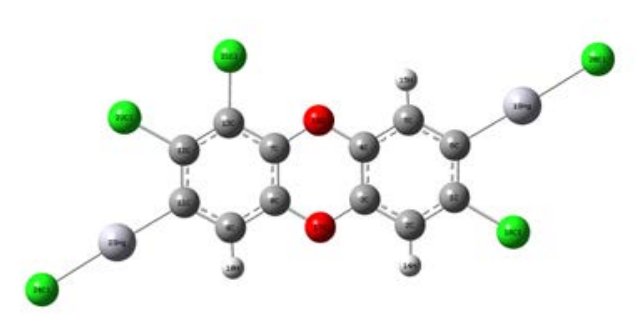

D2: $1,2,6-\mathrm{Cl} 3,7 \mathrm{HgCl}$ PCDD

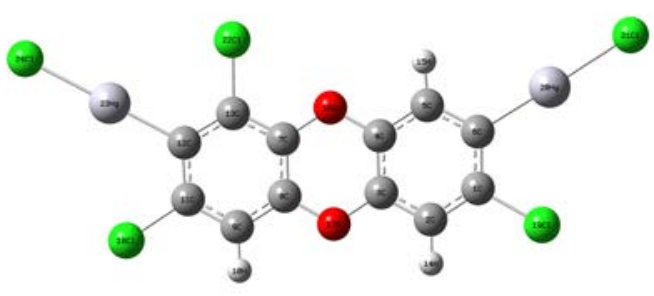

D4: $\quad$ 1, 3, 6-Cl 2, 7HgCl PCDD 


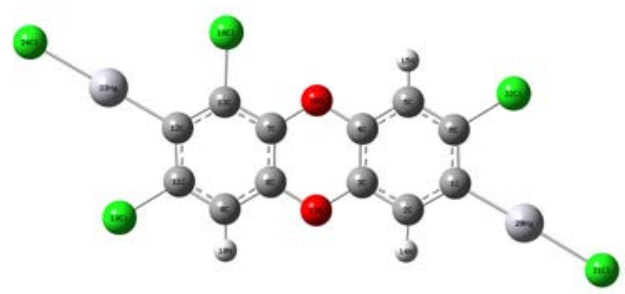

D5: 1, 3, 6-Cl 2, 7-HgCl PCDD

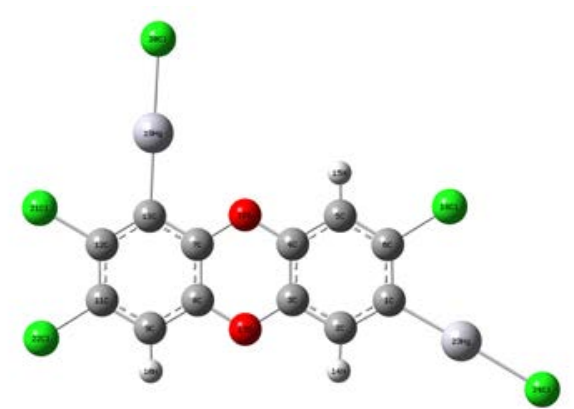

D7: 2, 3, 7-Cl 1, 6-HgCl PCDD

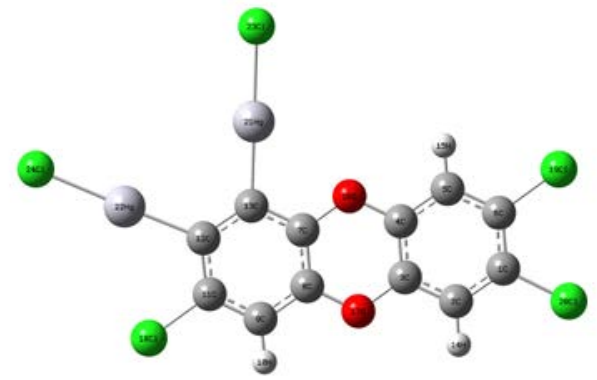

D9: 3, 6, 7-Cl 1, 2-HgCl PCDD

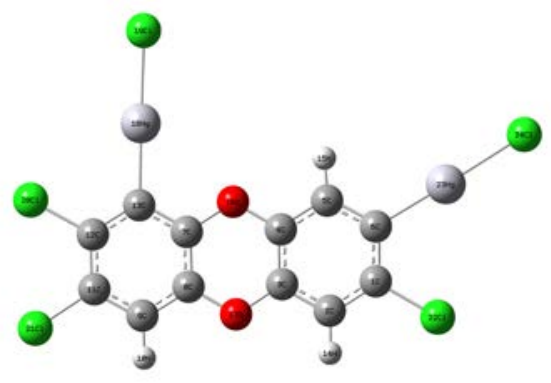

D6: 2, 3, 6-Cl 1, 7HgCl PCDD

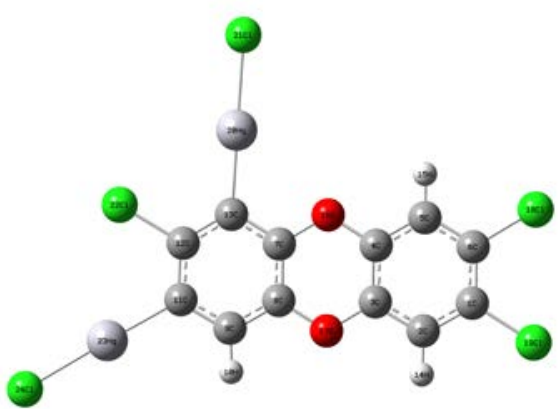

D8: 2, 6, 7-Cl 1, 3-HgCl PCDD

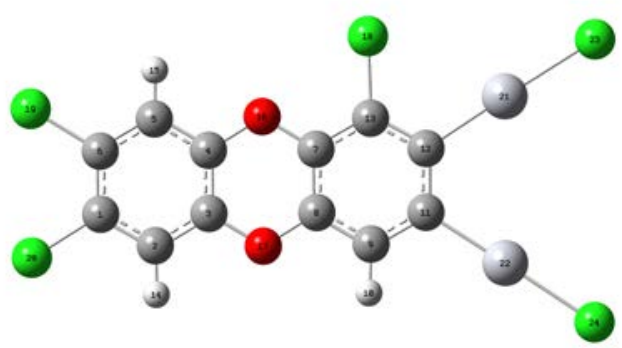

D10: 1, 2, 6-Cl 3, 7HgCl PCDD

Fig1. 3cl-2HgCl-Dioxins

\section{Result And Analysis}

\subsection{Physical Structure.}

1, 2, 3, 6, 7-Dioxins have widely sources and highly toxic. The influence on electrostatic energy and HOMO/LUMO are studied for $\mathrm{HgCl}$ groups in different attached positions. The atomic separations for the optimized structures have shown in picture 2 .

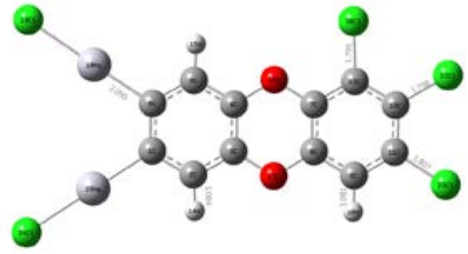

D1: 1, 2, 3-3Cl 6, 7-2HgCl PCDD

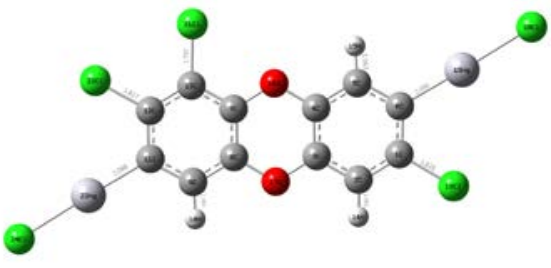

D2: 1 , 2, 6-3Cl 3, 7-2HgCl PCDD 


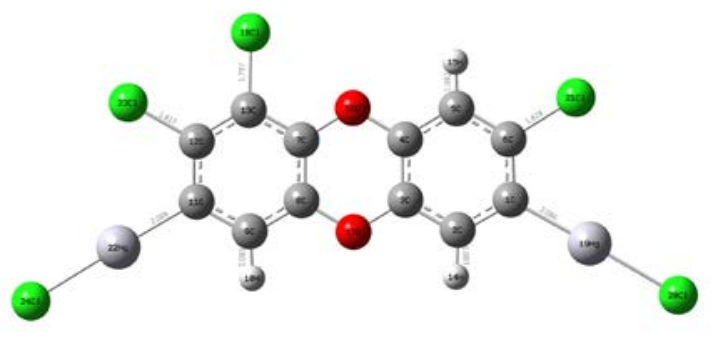

D3: 1, 2, 7-3Cl 3, 6-2HgCl PCDD

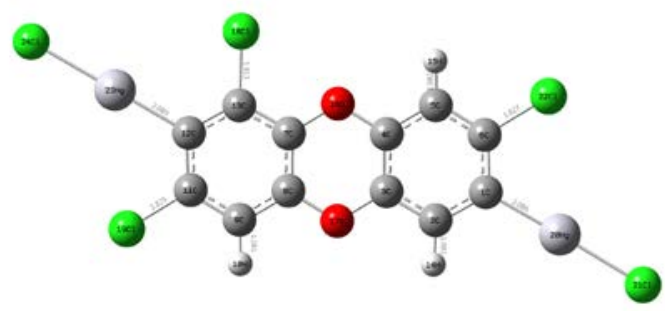

D5: $1,3,6-3 \mathrm{Cl}$ 2, 7-HgCl PCDD

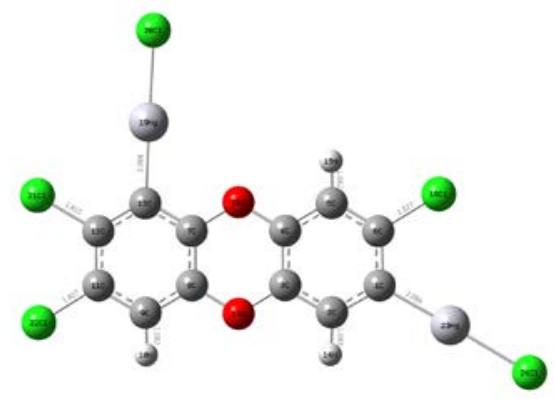

D7: 2, 3, 7-3Cl 1, 6-2HgCl PCDD

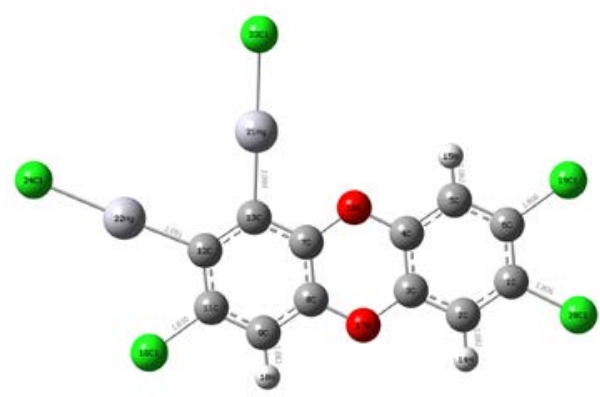

D9: 3, 6, 7-3Cl 1, 2-2HgCl PCDD

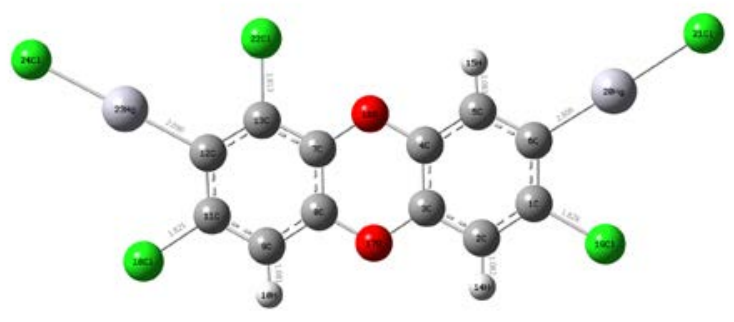

D4: $1,3,6-3 \mathrm{Cl}$ 2, 7-2HgCl PCDD

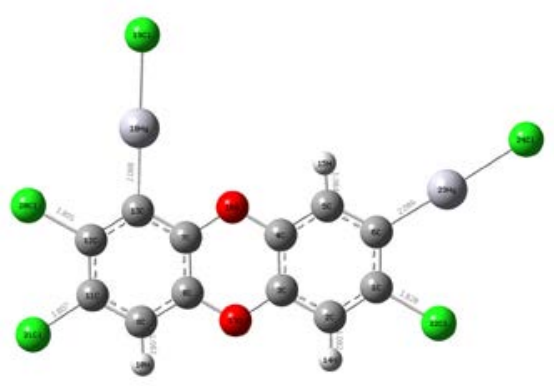

D6: 2, 3, 6-Cl 1, 7-2HgCl PCDD

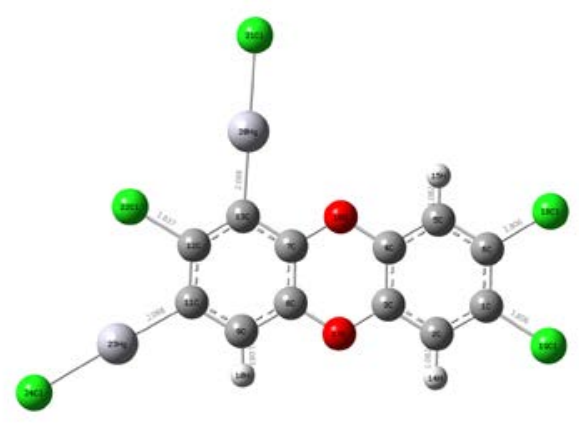

D8: 2, 6, 7-3Cl 1, 3-2HgCl PCDD

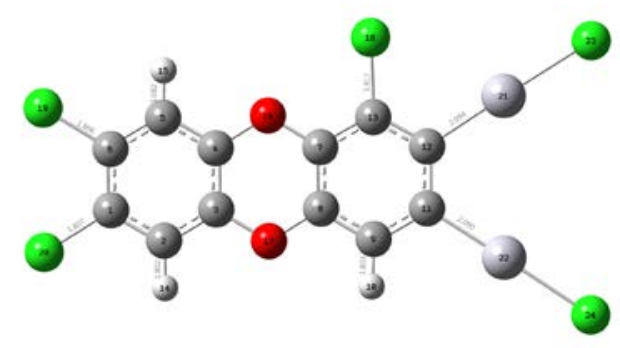

D10: $1,2,6-3 \mathrm{Cl} 3,7-2 \mathrm{HgCl}$ PCDD

Fig2. : The atomic separation and angle in optimized 2cl-2HgCl-Dioxins

There are some conclusions which are obtained from the data of four Dioxins' bond length in Fig4, the length of c-cl bond is $1.795 \sim 1.837 \AA$, The bond lengths of c-cl change a lot with the different positions of c-hg bond, the bond length will increase when it is close to c-hg bonds, and the bond energy is lower, which means that the bond of c-hg bond influence the stability of c-cl bond. The reason of this problem may be that the c-hg bonds have interferences on the structure stability, so that

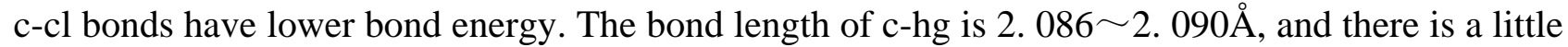
gap between every different structure. The c-hg bond length increase only when c-hg bonds are closed to the oxygen bridge, and its bond energy is lower. 


\section{2 HOMO/LUMO.}

HOMO represents Highest Occupied Molecular Orbital, and LUMO represents Lowest Unoccupied Molecular Orbital. According to the frontier orbital theory, they are all frontier orbitals. HOMO and LUMO influence the active sites of chemical reactions, the other energy molecular orbitals have so little influence which can be ignored.

Optimizing the structures of polychlorinated and mercury chloride based dioxins on Gaussian 09 by the base of B3LYP/6-31G and SDD, then HOMO and LUMO come out, the sizes and locations of electrostatic potential extreme values are calculated after putting the optimized structure into Multiwfn. The HOMO/LUMO of polychlorinated and mercury chloride based dioxins show in the picture 3.
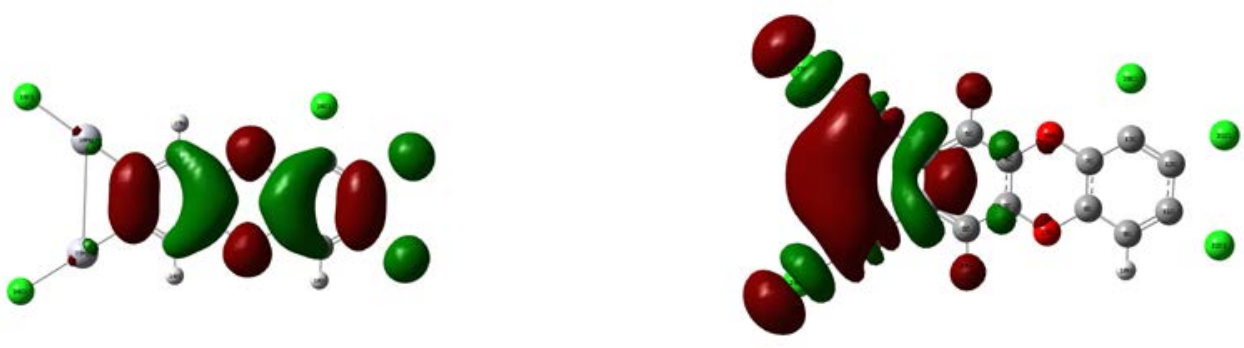

D1: (HOMO/LUMO)
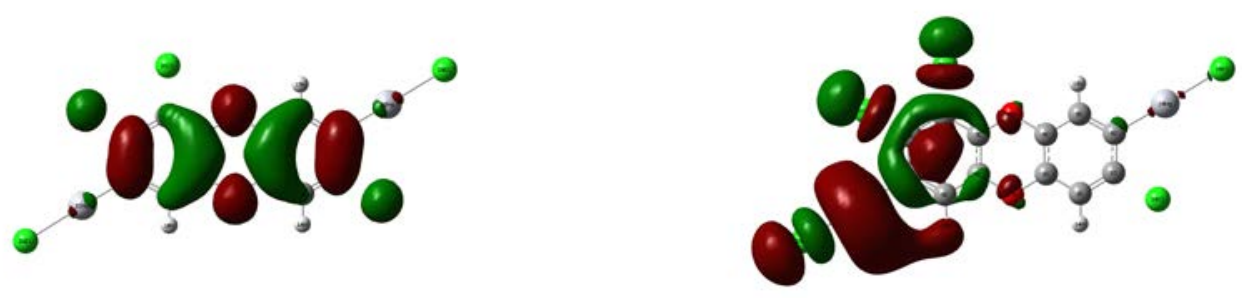

D2: (HOMO/LUMO)
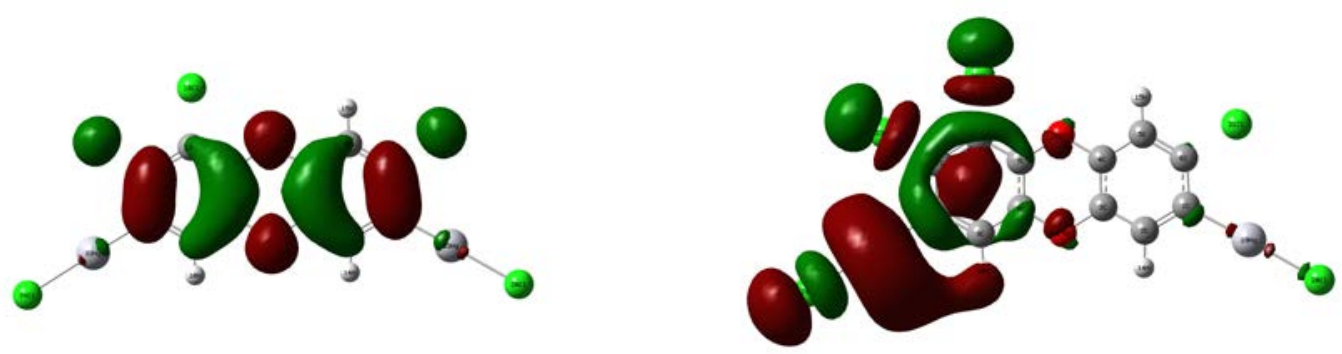

D3: (HOMO/LUMO)
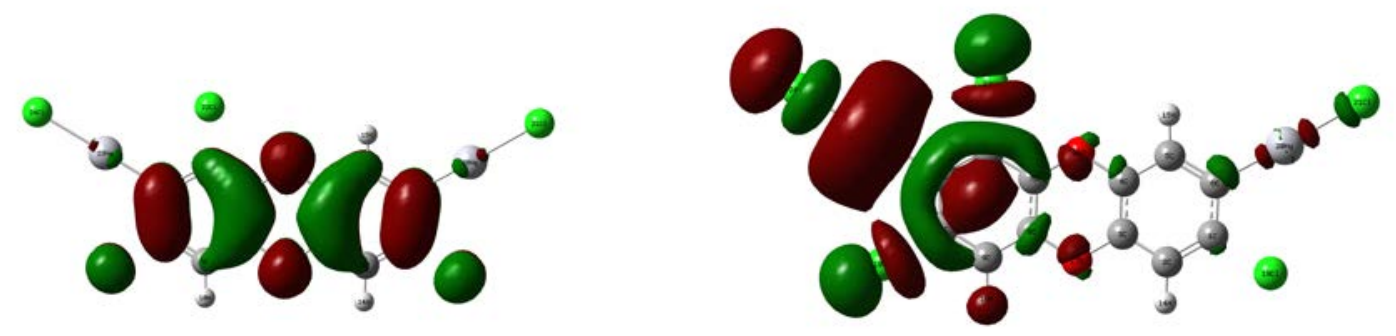

D4: (HOMO/LUMO) 

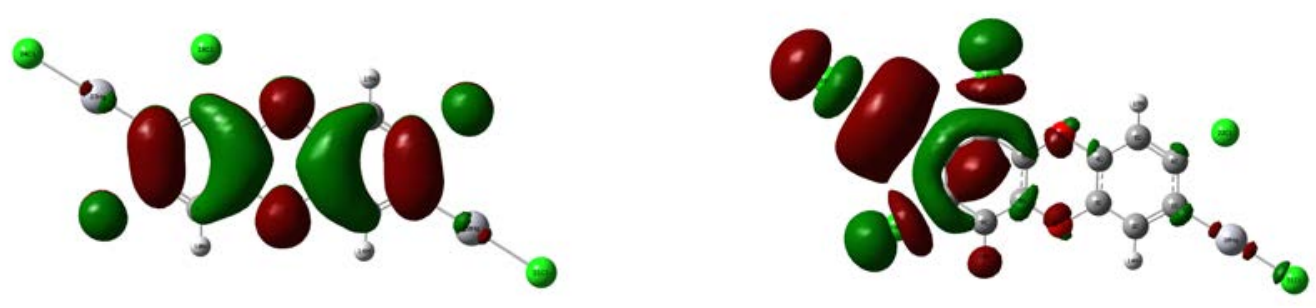

D5: (HOMO/LUMO)
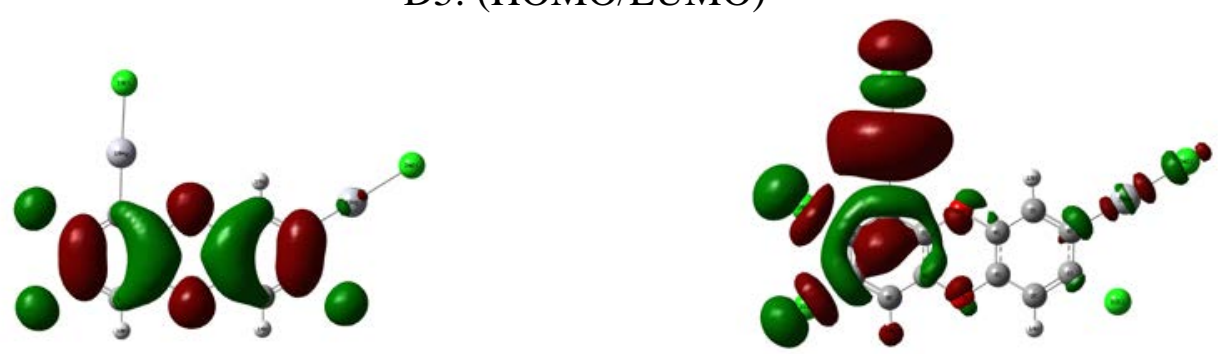

D6: (HOMO/LUMO)
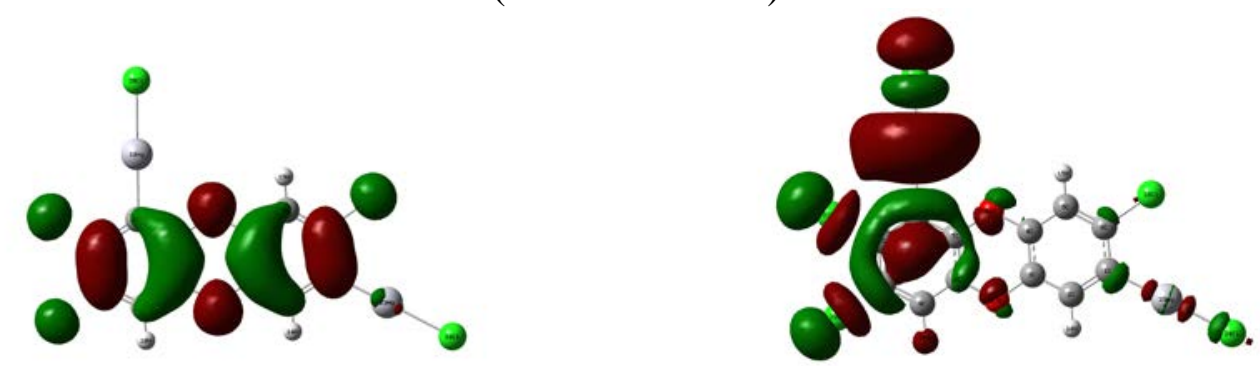

D7: (HOMO/LUMO)
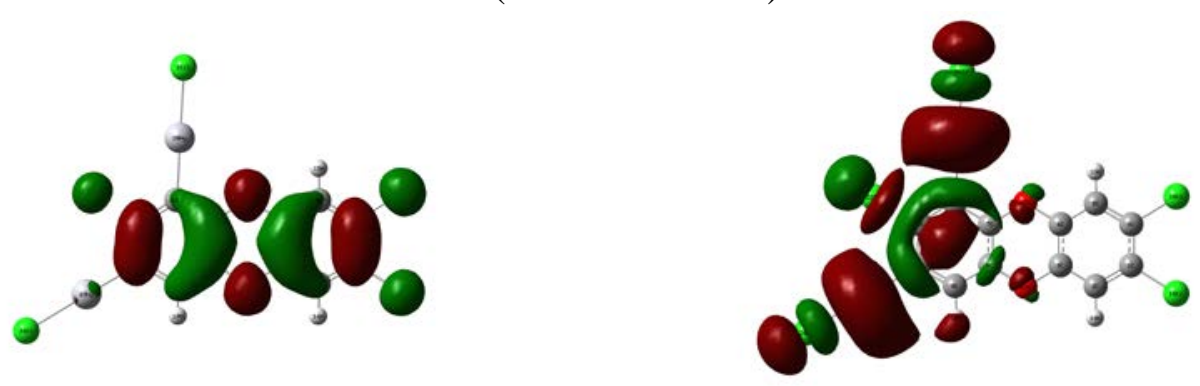

D8: (HOMO/LUMO)
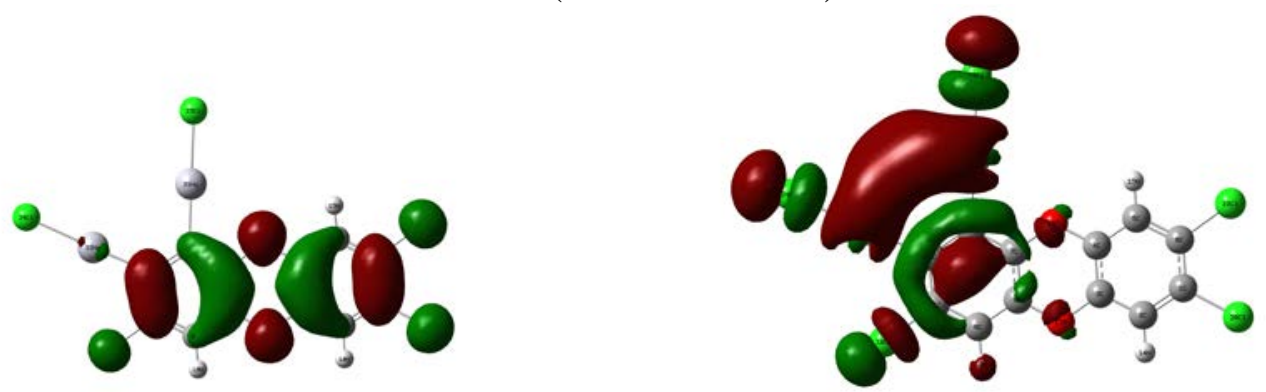

D9: (HOMO/LUMO) 

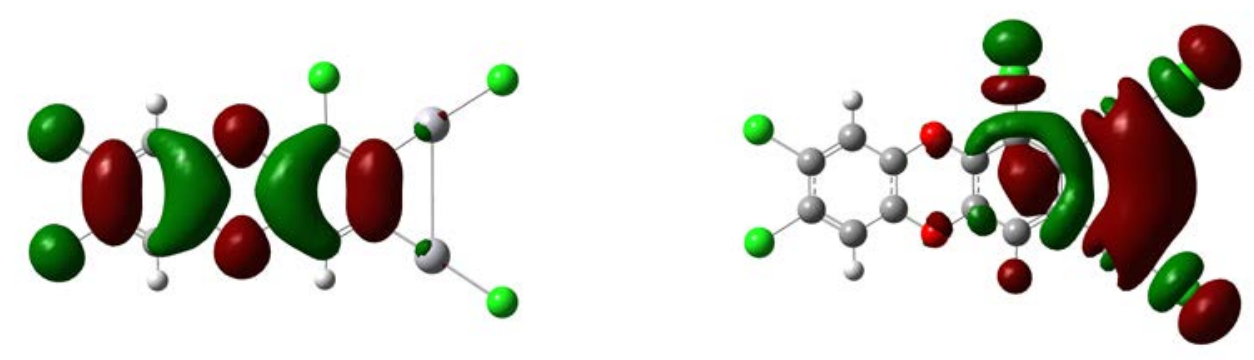

D10: (HOMO/LUMO)

Fig3. Polychlorinated and mercury chloride based Dioxins' HOMO (front) and LUMO (behind)

There are some conclusions learning from the HOMO/LUMO. In the picture of D1 LUMO, the electronic orbits on $\mathrm{HgCl}$ functional groups are dense, which means the electrons on the frontier molecular orbital in this area focused. According to the HOMO, all the atoms except the HgCl groups and h atom have complete electronic orbits. They are easily to adsorb electrons, which has a big probability to have a nucleophilic reaction. The electrostatic potential energy minimal value point in this group is $-22.35 \mathrm{kcal} / \mathrm{mol}$ which is on the $\mathrm{cl}$ atom of $\mathrm{Hg}-\mathrm{Cl}$ bonds. The electrostatic potential energy maximal value point is $30.09 \mathrm{kcal} / \mathrm{mol}$, which is on the middle position of oxygen bridges. In the same time, the electrostatic potential energy on $\mathrm{h}$ atom is $29.89 \mathrm{kcal} / \mathrm{mol}$, which is also high.

The HOMO and LUMO from D2 have different conclusions with D1.In LUMO of D2, there is a good orbit on the $\mathrm{HgCl}$ group which is close to the $\mathrm{Cl}$ nearing the oxygen bridge. The electrostatic potential energy minimal value point is $-21.69 \mathrm{kcal} / \mathrm{mol}$, which is on the $\mathrm{cl}$ atom of $\mathrm{HgCl}$ groups. The electrostatic potential energy maximal value point is $36.72 \mathrm{kcal} / \mathrm{mol}$, which is on the middle position of two $\mathrm{Hg}$ atoms. The electrostatic potential energy on h atom is $28.52 \mathrm{kcal} / \mathrm{mol}$, which is also high.As for D3 D8, their HOMO and LUMO are similar with D2. The electrostatic potential energy minimal value points are $-21.57 \mathrm{kcal} / \mathrm{mol},-21.97 \mathrm{kcal} / \mathrm{mol},-20.97 \mathrm{kcal} / \mathrm{mol},-21.34 \mathrm{kcal} / \mathrm{mol},-21.54 \mathrm{kcal} / \mathrm{mol}$ and $-20.69 \mathrm{kcal} / \mathrm{mol}$, which is on the $\mathrm{cl}$ atom of $\mathrm{HgCl}$ groups. The electrostatic potential energy maximal value points are $36.84 \mathrm{kcal} / \mathrm{mol}, 37.12 \mathrm{kcal} / \mathrm{mol}, 35.97 \mathrm{kcal} / \mathrm{mol}, 36.87 \mathrm{kcal} / \mathrm{mol}$ $37.01 \mathrm{kcal} / \mathrm{mol}$ and $36.77 \mathrm{kcal} / \mathrm{mol}$ which are on the $\mathrm{Hg}$ nearing oxygen bridges. The electrostatic potential energies on $\mathrm{h}$ atoms are $29.91 \mathrm{kcal} / \mathrm{mol}, 28.71 \mathrm{kcal} / \mathrm{mol} 28.96 \mathrm{kcal} / \mathrm{mol} 29.75 \mathrm{kcal} / \mathrm{mol}$ $29.91 \mathrm{kcal} / \mathrm{mol}$ and $28.63 \mathrm{kcal} / \mathrm{mol}$, which are also high.

In LUMO of D9, D10, there are big frontier orbitals on the $\mathrm{Cl}$ atoms of $\mathrm{HgCl}$ groups, which are likely to release electrons to have a electrophilic reaction. In HOMO, there is probably to have a nucleophilic reaction on the c-cl bonds, there is a small orbit on $\mathrm{HgCl}$ groups and $\mathrm{h}$ atoms. The electrostatic potential energy minimal value point is $-21.12 \mathrm{kcal} / \mathrm{mol}$, which is on the $\mathrm{cl}$ atom and hg atom in this group. The electrostatic potential energy maximal value point is $38.12 \mathrm{kcal} / \mathrm{mol}$, which is on the middle position of two $\mathrm{Hg}$ atoms. The electrostatic potential energy on $\mathrm{h}$ atom is $28.32 \mathrm{kcal} / \mathrm{mol}$, which is also high. It can be learned that both of two $\mathrm{HgCl}$ bonds on the same side have a big opportunity to release the electrons on $\mathrm{cl}$ atoms of $\mathrm{HgCl}$ groups, which can increase the reactivity of reaction.

\section{Summary}

1), The bond lengths of $\mathrm{C}-\mathrm{Cl}$ bonds are $1.795 \sim 1.837 \AA$, which are changed for $\mathrm{C}-\mathrm{Hg}$ bonds' positions, the lengths increase when they close to the $\mathrm{C}-\mathrm{Hg}$ bonds, which means the stability of $\mathrm{C}-\mathrm{Cl}$ bonds can be influenced by C-Hg bonds. The C-Hg bonds may influence the bond energy of C-Cl bonds by affecting the structure stability. The bond lengths of $\mathrm{C}-\mathrm{Hg}$ bonds are $2.086 \sim 2.090 \AA$, which are invariant.

2), In HOMO, the electron orbits concentrate on $\mathrm{HgCl}$ groups especially the chlorine, which are likely to have nucleophilic reactions. In LUMO, there is a good frontier orbits on all but the $\mathrm{HgCl}$ groups and $\mathrm{H}$ atoms, especially on chlorine of $\mathrm{C}-\mathrm{Cl}$ bonds, which is likely to adsorb electrons to have a electrophilic reaction. 
3), The electrostatic potential energy minimal value is $-22.35 \sim-20.69 \mathrm{kcal} / \mathrm{mol}$ on chlorine of $\mathrm{HgCl}$ groups; The electrostatic potential energy maximal value is $35.97 \sim 38.12 \mathrm{kcal} / \mathrm{mol}$ on $\mathrm{Hg}$ of $\mathrm{HgCl}$ groups nearing $\mathrm{H}$ atoms. The electrostatic potential energies are also big on $\mathrm{H}$ atoms.

\section{References}

[1]. Bu qing-yu, Xu hai-hong, Li jia,et al. Analysis on mercury pollution control of coal power plant in China [J]. Environmental Protection. Vol. 42 (2014) No.1,p. 119-128.

[2]. Fu jian-jie, Wang ya-hua, Zhou,lin-jia, et al. Pollution Status and Perspectives of Persistent Toxic Substances in E-Waste Dismantling Area in China[J].Progress in Chemistry.Vol. 8 (2011) No.8,p. 1755-1768.

[3]. Ibrahim F B, Adie D B, Giwa A R, et al.Material Flow Analysis of Electronic Wastes (e-Wastes) in Lagos,Nigeria[J].Journal of Environmental Protection. Vol. 4 (2013) No.9,p. 1011-1017.

[4]. Chu shao-gang, Tong yi-ping, et al. The distribution and environmental behavior of PCBs in typical polluted areas[J]. Acta Scientiae Circumstantiae. Vol. 15 (1995) No.4,p. 423-432

[5]. Luo yong-ming, Teng ying, Li qing-bo, et al. Soil Environmental Quality And Remediation In Yangzi river delta region I. Composition And Pollution Of Polychlorinated Dibenzo-p-Dioxins And Dibenzofurans (PCDD/Fs) In A Typical Farmland[J]. ACTA PEDOLOGICA SINICA. Vol. 42 (2005) No.4,p. 570-576.

[6]. Zhang Gang: Study on PCDD/F and heavy emission characteristics and control technology during municipal solid waste incineration [D]. (Doctoral dissertation, South China University of Technology, 2013)p. 1-83.

[7]. Hu D, Zhang W, Chen L, et al. Mercury emissions from waste combustion in China from 2004 to 2010[J]. Atmospheric Environment, Vol. 63 (2012) No.4,p. 359-366.

[8]. Tan Man-yu. Comparison of waste incineration pollution control standards in domestic and foreign [J]. Science and Technology Innovate, Vol. 1 (2016) No.3,p. 95-96.

[9]. CHEN Tong, LI Xiao-dong, YAN Jian-hua.et al. Distribution Of Polychlorinated DIBENZO-p-DIOXINS And DIBENZOFURANS(PCDD/Fs)In Fly ashes from Municipal Solid Waste Incinerations[J]. Journal of Fuel Chemistry and Technology. Vol. 1 (2004) No.4,p.:59-64.

[10]. Jensen S, Jernelöv A. Biological methylation of mercury in aquatic organisms [J]. Nature. Vol. 223 (1969) No.5207, p.:753-4.

[11]. Yu Wan-ni. Mechanism Study on the Homogeneous Gas-phase Formation of PXDD/Fs from Halogenated Phenols as Precursors. (Doctoral dissertation, Shandong University, 2013).p. 1-93.

[12]. Zhang Jian-ying, Zhang Yu, Yu-he K, et al. Theoretical studies on vibrational spectra of some halides of Group IIB elements.[J]. Spectrochimica Acta Part A Molecular \& Biomolecular Spectroscopy. Vol. 60 (2004) No.3, p.679-88.

[13]. Gao Zheng-yang Lv Shao-kun. Mechanism Study on $\mathrm{Hg}$ adsorption by $\mathrm{MnO}_{2}$-modified Activated Carbons [J]. Journal of Chinese Society of Power Engineering Vol.35 (2016) No.11, p. 923-928. 